\title{
Ileal mucosal absorption of bile acid in man: validation of a miniature flux chamber technique
}

\author{
K B Hosie, R J Davie, B Panagamuwa, S Grobler, M R B Keighley, N J Birch
}

\begin{abstract}
A method that allows the quantitative assessment of ileal mucosal cell uptake and transport of bile acids in mucosal biopsy specimens has been validated. Viability of the tissue was confirmed by maintenance of normal cell morphology, wet weight, extracellular space, porosity to polyethylene glycol-900, lactate dehydrogenase release, and transmucosal potential difference. Using ${ }^{14} \mathrm{C}$-taurocholic acid, absorption was shown to be directional, capable of working against a concentration gradient, reduced by metabolic inhibitors, and sodium dependent. The system showed saturation kinetics with an estimated $\mathbf{K}_{\mathrm{m}}$ of $10 \mu \mathrm{mol} / \mathrm{l}$. At a standard substrate concentration of $10 \mu \mathrm{mol} / \mathrm{l}$ ileal mucosal bile acid absorption was compared in patients with colorectal cancer $(n=6)$, ulcerative colitis $(n=10)$, and slow transit constipation $(n=8)$. There was no significant difference in tissue uptake or transport between the three groups.
\end{abstract}

Our understanding of bile acid absorption has been obtained from experiments in animals, together with only a few in vivo perfusion studies in man. ${ }^{12}$ The paucity of studies in man reflects the inaccessibility of the small bowel and the lack of a suitable technique to study intact mucosal function in the limited amount of human tissue available.

This paper describes the validation in human tissue of a technique developed in animal studies that allows a quantitative assessment of tissue uptake (movement across apical and basolateral membrane) and transport (movement across the intact mucosal sheet) of bile acids in small biopsy specimens of ileal mucosa using a miniature flux chamber. The experimental method has been developed from a technique used successfully to investigate water, ${ }^{3}$ lithium, ${ }^{45}$ and $z^{2}{ }^{6}{ }^{6}$ absorption in the rodent small intestine.

Bile acid reabsorption occurs in the terminal ileum..$^{7-13}$ This process is thought to be active for the following reasons: it can occur against a concentration gradient and also when the electrochemical gradient is zero; absorption is blocked by metabolic inhibitors or anoxia and is dependent on the presence of sodium ions in the gut lumen; and the kinetics of absorption display saturation phenomena. Passive absorption is also present and two mechanisms for this have been proposed - ionic diffusion and non-ionic diffusion. ${ }^{10-12}$ The relative contribution of the active and passive components is determined by the principles governing transport of weak acids and depends on intraluminal $\mathrm{pH}$, the $\mathrm{pKa}$ of the particular bile acid, and the permeability and partition coefficients of the ionic and non-ionic species. ${ }^{10121415}$

\section{Methods}

All materials were of Analar or similar grade. Taurocholic acid was obtained from the Sigma Chemical Company, Poole, UK. Radioisotopically labelled bile acids were obtained from Amersham International (UK), and New England Nuclear, Du Pont (Germany).

TISSUE

The most distal portion of terminal ileum $(2 \mathrm{~cm})$ was obtained from 25 patients undergoing surgical resection for slow transit constipation $(n=9)$, colorectal cancer $(n=6)$, and ulcerative colitis $(n=10)$. Where possible, mesenteric blood vessels were divided immediately before resection to ensure minimal disruption of tissue perfusion and oxygenation. Transport time from theatre to the laboratory averaged less than two minutes.

\section{EXPERIMENTAL METHODS}

Experiments were carried out using a small flux chamber described by Lauterbach, ${ }^{3}$ (Fig 1). Unless otherwise stated, a standard Krebs buffer, ${ }^{16} \mathrm{pH} 6 \cdot 0,37^{\circ} \mathrm{C}$ was used as transport and incubation medium. All tests were performed over 45 minutes.

Resected ileum was placed mucosal side down on a cork mat and the overlying connective tissue and muscle layers removed by sharp dissection. The isolated mucosa was then supported on a piece of fine nylon mesh and small sections approximately $6 \mathrm{~mm}^{2}$ were cut and placed between two polyvinyl chloride membranes to occlude a prepunched circular porthole of $5 \mathrm{~mm}$ diameter. The assembled tissue sample was clamped between two perspex hemichambers and the whole assembly secured using a U shaped tube clamp.

Buffer $\left(200 \mathrm{~mm}^{3}\right)$ was simultaneously added to each hemichamber. Oxygenation and stirring were achieved by passing moistened $95 \% \mathrm{O}_{2} / 5 \%$ $\mathrm{CO}_{2}$ through fine drillings in the chamber wall. The concentrations of electrolytes and substrate were identical on each side of the mucosa at the start of each experiment. Substrate movement was measured using isotopically labelled markers.

At the end of the experiment buffer solutions were collected from each hemichamber for analysis. The exact area of tissue exposed to the buffer solutions was removed using a specially designed punch, ${ }^{3}$ weighed, and then dis- 


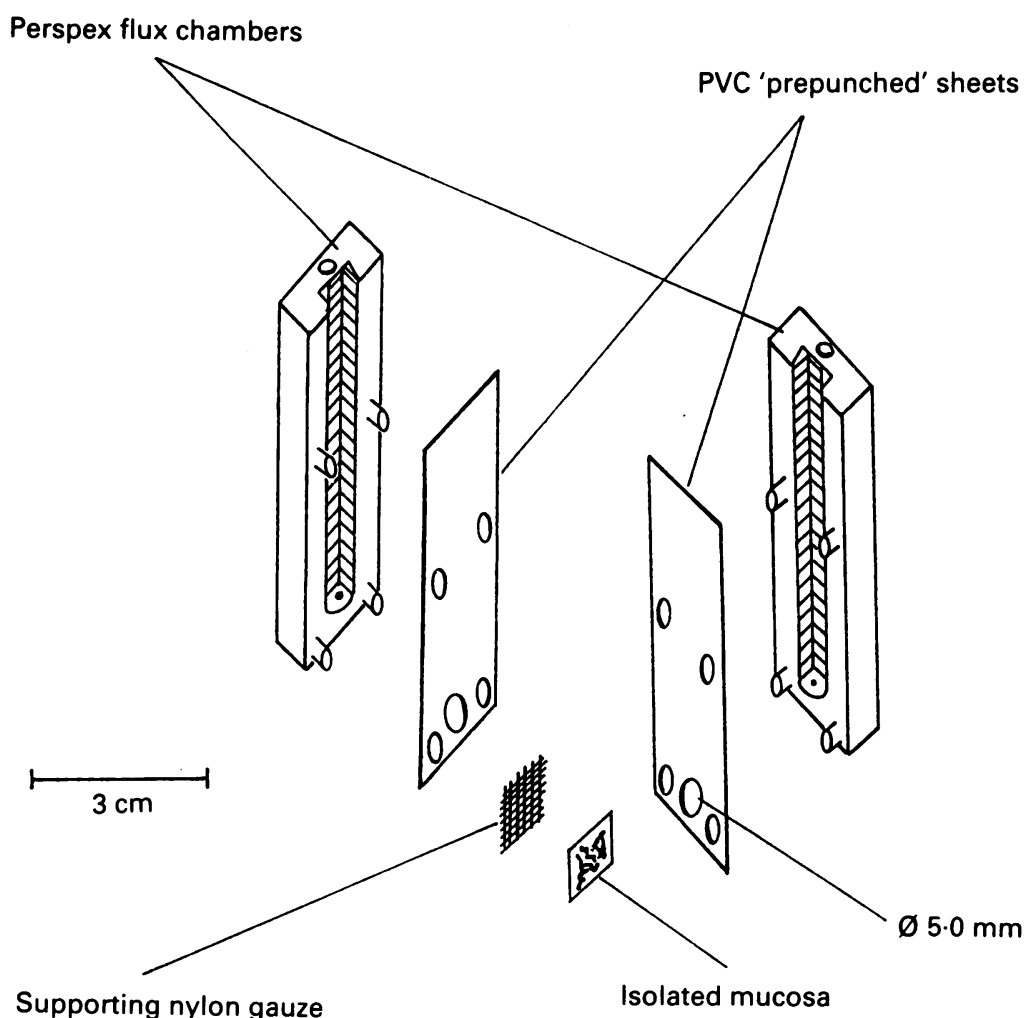

Figure 1: Exploded view of miniature flux chamber. (Reproduced from reference 3 with kind permission of F Lauterbach and N S Arch Pharmacol.)

solved using the tissue solubiliser 'NCS' (Amersham) before analysis. All isotopes were counted using a Beckman LS6800 liquid scintillation counter.

\section{TISSUE VIABILITY STUDIES}

To show that the tissue remained physiologically and structurally viable in the flux chamber and behaved in a reproducible manner, several tests were performed on each preparation.

\section{Histology}

Isolated mucosa was prepared as previously described. Samples were taken before and after removal of the muscle layers and following 45 minutes incubation in standard Krebs buffer. After dehydration in formalin before wax impregnation, longitudinal sections were cut and stained using haemotoxylin and eosin.

\section{Lactate dehydrogenase release}

Lactate dehydrogenase was assayed using a diagnostic test kit (Sigma no 228). After 45 minutes incubation in standard buffer or buffer containing bile acid, both buffer and tissue were retrieved for analysis. The tissue was homogenised in $0.9 \%$ saline using a Tri-R blender (Camlab, UK) and lactate dehydrogenase release was expressed as a percentage of the total activity in tissue and buffer.

\section{Potential difference}

Transmembrane potential difference was measured by connecting agar salt bridges from either side of the preparation to calomel half-cell electrodes. The potential was measured using a Phillips PW9403 voltmeter. Agar bridges were constructed using $3 \mathrm{~mol} / 1 \mathrm{KCl}$ in $4 \%$ agar in polypropylene tubing, (id, $0.63 \mathrm{~mm}$ ). Potentials were recorded as required. The effects of manipulation in the buffer of the following substrates was investigated:

(i) A combination of sodium fluoride (10 mmol/l) and ouabain, $(1.0 \mathrm{mmol} / \mathrm{l})$;

(ii) 2, 4-Dinitrophenol, $(1.0 \mathrm{mmol} / \mathrm{l})$;

(iii) Taurocholic acid, $(10 \mu \mathrm{mol} / \mathrm{l})$;

(iv) Glucose, $(28 \mathrm{mmol} / \mathrm{l})$;

(v) Oxygen addition after experimental anoxia.

\section{Measurement of tissue wet weight and extracellular} space

Experiments were conducted over $0.5,1,2,5$, $10,20,30,45$, and 60 minute time periods. After incubation, the tissue was collected and weighed before solubilisation.

Tissue extracellular space was measured using the marker polyethylene glycol-900 (PEG, $\mathrm{M}_{\mathrm{r}}$ 800-1000). Polyethylene glycols are ideal for this purpose as they have been shown to be nontoxic, not degraded by intestinal bacteria, and not subject to metabolism after absorption. ${ }^{17} 18$ Tissue extracellular space values at each time period were calculated.

\section{TAUROCHOLIC ACID KINETICS: DETERMINATION OF} APPARENT $\mathrm{K}_{\mathrm{M}}$ AND $\mathrm{J}_{\mathrm{MAX}}$

Taurocholic acid was chosen as the substrate of study as it is the bile acid most dependent on active transport mechanisms. ${ }^{8}$ All experiments were carried out at a standard $\mathrm{pH}$ of 6.0 since this is within the normal range of ileal pH. ${ }^{190}$ Kinetics were studied over a range of taurocholic acid concentrations from $1 \cdot 0-500 \cdot 0 \mu \mathrm{mol} / 1$. Values above this concentration were unreliable because of the toxic nature of taurocholic acid to cells at higher concentrations. The apparent $\mathrm{K}_{\mathrm{m}}$ and apparent $\mathrm{J}_{\max }$ of taurocholic acid were calculated using a method adapted from Debnam and Levin. ${ }^{21}$ This allows for the presence of both active and passive absorption processes in the normal mucosa. It follows that inhibition or saturation of the active process will result in the overall rate of absorption being determined by those passive processes unaffected by the inhibitor. In these cases the kinetics are linear with respect to substrate concentration. As a consequence the two component system absorption kinetics would be expected to follow the modified Michaelis Menten equation:

$$
J=\frac{j \star[S]}{K m+[S]}+k \pm[S]
$$

which describes a relationship between the absorption rate $J$ and luminal substrate concentration [S], where $j$ is the apparent maximum rate of absorption, $\mathrm{K}_{\mathrm{m}}$ is the apparent substrate concentration at half-maximum rate of absorption (Michaelis constant), and $\mathrm{k}$ is a rate constant.

A standard concentration of taurocholic acid $(10 \mu \mathrm{mol} / \mathrm{l})$ was chosen on the basis of pre- 

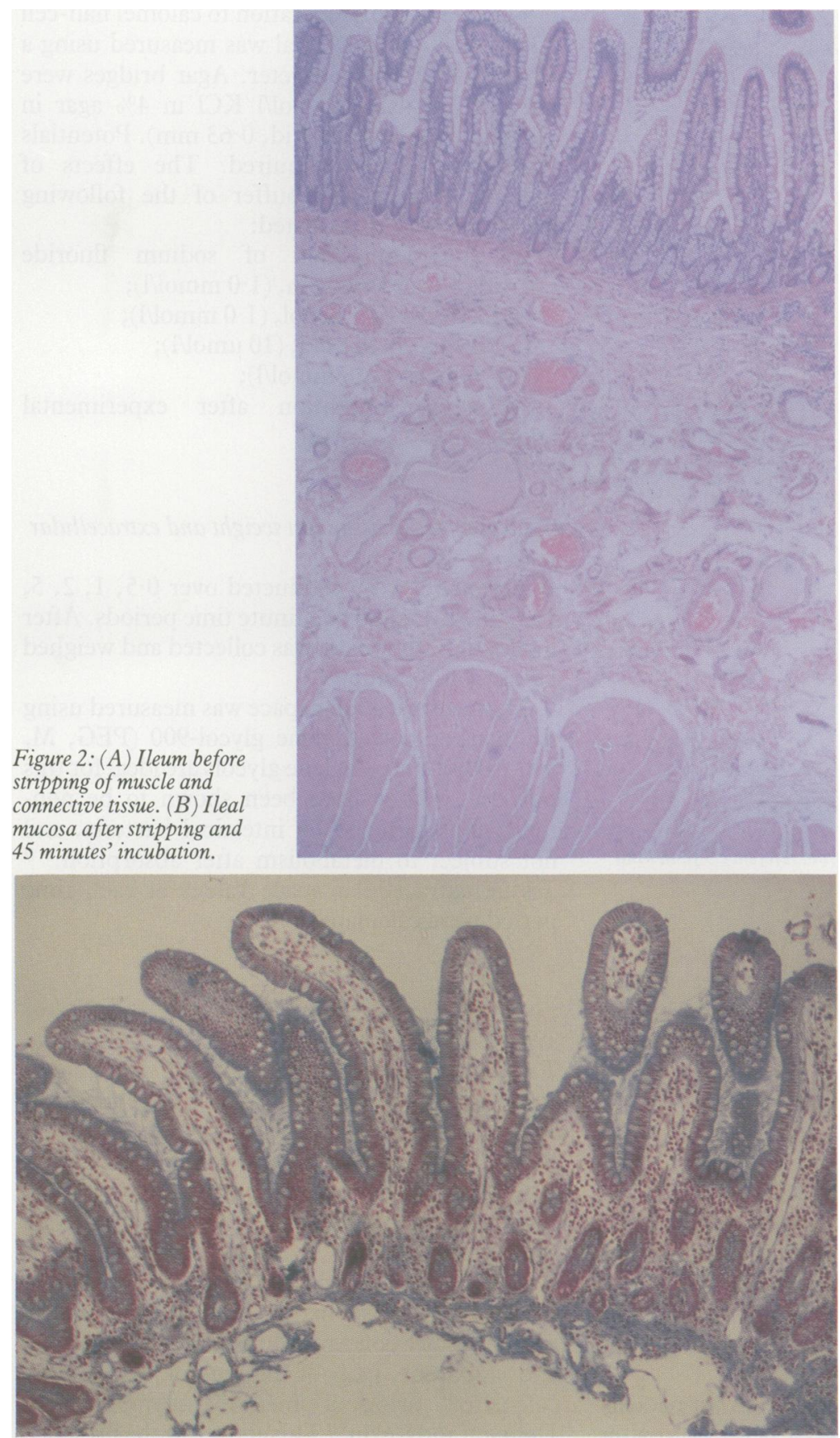

liminary kinetic studies and used in subsequent experiments.

\section{Time relationship of absorption processes}

Uptake and transport were measured using our standard buffer with $10 \mu \mathrm{mol} / \mathrm{l}$ taurocholic acid over incubation periods of $1,2,5,10,20,30,45$, and 60 minutes.

\section{Inhibitor studies}

Uptake and transport were measured in the presence of (1) 2, 4-dinitrophenol $(1.0 \mathrm{mmol} / \mathrm{l})$ or (2) a mixture of sodium fluoride $(\mathrm{NaF}$, $10.0 \mathrm{mmol} / \mathrm{l})$ and ouabain $(1.0 \mathrm{mmol} / \mathrm{l})$. Cox and Peters ${ }^{22}$ have shown that incomplete inhibition of iron uptake, an active process, occurred in human duodenal biopsy specimens if either inhibitor was used alone.

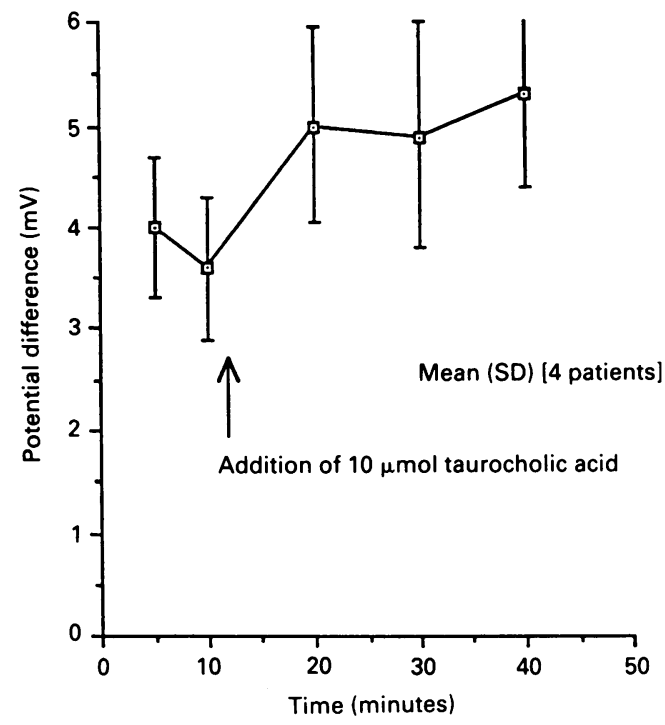

Figure 3: Effect of addition of taurocholic acid on potential difference.

\section{Absorption and secretion}

Placing the labelled ${ }^{1+} \mathrm{C}$-taurocholic acid solution either in the mucosal or serosal compartment of the chamber allowed comparison of absorption and secretion.

\section{Effect of sodium depletion}

The concentration of sodium in the test buffer was reduced by the equimolar replacement of sodium chloride with choline chloride. The final sodium concentration was $24 \mathrm{mmol} / \mathrm{l}$, compared with $112 \mathrm{mmol} / \mathrm{l}$ in the standard buffer.

\section{REPRODUCIBILITY}

In 10 patients suffering from either constipation, ulcerative colitis, or cancer, tissue samples were dissected and mounted as previously described. Between five and 13 replicates were obtained from each subject.

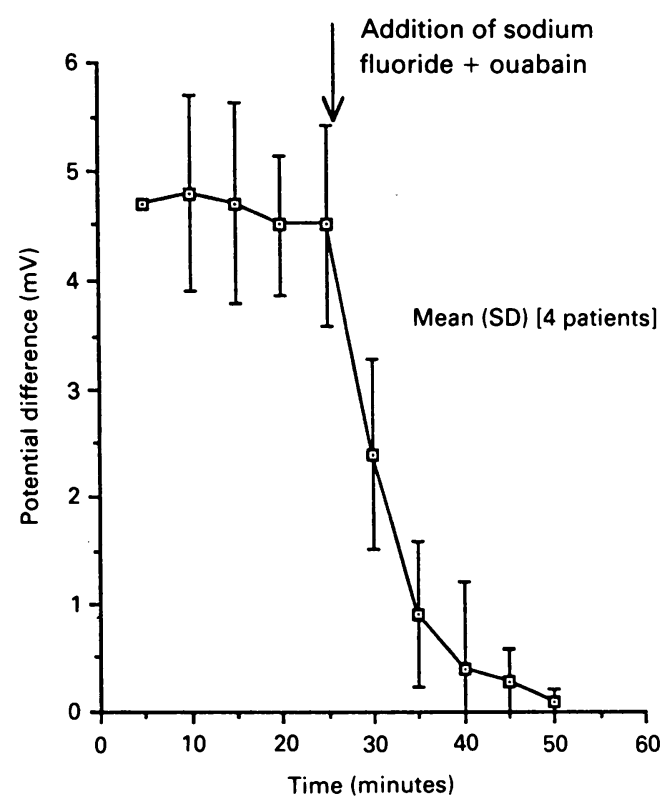

Figure 4: Effect of inhibitors on potential difference. 
COMPARISON OF CLINICAL GROUPS

Using the method as above, a standard buffer with $10 \mu \mathrm{mol} / \mathrm{l}$ of taurocholic acid was used to compare ileal mucosal function in patients with constipation $(n=8)$, ulcerative colitis $(n=10)$, and cancer $(n=6)$.

\section{STATISTICAL ANALYSIS}

Results are expressed as mean (SD), with the number of chamber experiments and patient number alongside. Statistical significance was accepted when $\mathrm{p}<0 \cdot 05$. (Students $t$ test.)

ETHICAL COMMITTEE APPROVAL

Approval for this study was obtained from the Birmingham Hospitals Research Ethical Committee.

\section{Results}

\section{TISSUE VIABILITY STUDIES}

\section{Histology}

Histological sections confirmed separation of the muscle layers from the mucosa along the lamina propria. There was no histological damage to the mucosa as a result of the stripping process or subsequent incubation in an experimental chamber (Fig 2).

\section{Lactate dehydrogenase release}

After stripping of the muscle layers and 45 minutes' incubation, a mean (SD) of $4 \cdot 35 \%(3 \cdot 0)$ $(n=16)$ of the total lactate dehydrogenase present was released into the standard buffer. With bile acid present, a mean (SD) of $4 \cdot 0 \%(2 \cdot 76)(n=16)$ of total lactate dehydrogenase was released.

\section{Transmucosal potential difference}

A consistent mean potential difference exceeding

TABLE I Changes in tissue wet weight (mg) and extracellular space volume $(\mu l)$ with time over the 45 minute incubation period

\begin{tabular}{|c|c|c|c|c|}
\hline \multicolumn{5}{|c|}{ (A) Tissue wet weight } \\
\hline $\begin{array}{l}\text { Time } \\
(\text { min })\end{array}$ & Mean & $(S D)$ & $\begin{array}{l}\text { No } \\
\text { (patient) }\end{array}$ & $\begin{array}{l}\text { No } \\
\text { (chambers) }\end{array}$ \\
\hline $\begin{array}{r}0.5 \\
1.0 \\
2.0 \\
5.0 \\
10.0 \\
30.0 \\
45.0\end{array}$ & $\begin{array}{l}21 \cdot 8 \\
26 \cdot 3 \\
26 \cdot 6 \\
25 \cdot 0 \\
23 \cdot 4 \\
26 \cdot 9 \\
25 \cdot 4\end{array}$ & $\begin{array}{l}5 \cdot 1 \\
8 \cdot 4 \\
6 \cdot 7 \\
6 \cdot 6 \\
5 \cdot 0 \\
4 \cdot 0 \\
6 \cdot 7\end{array}$ & $\begin{array}{l}2 \\
3 \\
4 \\
4 \\
3 \\
3 \\
8\end{array}$ & $\begin{array}{r}6 \\
11 \\
14 \\
14 \\
11 \\
11 \\
176\end{array}$ \\
\hline
\end{tabular}

(B) Extracellular space

\begin{tabular}{rrrlc}
\hline $\begin{array}{c}\text { Time } \\
\text { (min) }\end{array}$ & Mean & (SD) & $\begin{array}{l}\text { No } \\
\text { (patient) }\end{array}$ & $\begin{array}{l}\text { No } \\
\text { (chambers) }\end{array}$ \\
\hline $0.5^{\star}$ & 9.61 & 1.12 & 2 & 5 \\
1.0 & 16.76 & 4.56 & 4 & 14 \\
2.0 & 15.36 & 5.60 & 4 & 11 \\
5.0 & 14.24 & 4.26 & 4 & 14 \\
10.0 & 16.39 & 1.11 & 2 & 5 \\
20.0 & 15.94 & 2.65 & 2 & 8 \\
30.0 & 16.53 & 3.55 & 2 & 6 \\
45.0 & 17.06 & 6.15 & 5 & 130 \\
\hline
\end{tabular}

*The extracellular space at $0.5 \mathrm{~min}$ represents incomplete equilibration with the bulk phase buffer.
$4.0 \mathrm{mV}$ was obtained in the cell with ileal mucosa from each of 11 patients. This potential difference was maintained for at least 60 minutes, a period longer than our normal experimental time of 45 minutes. Further studies have shown that the maintained potential difference was not an artefact since stimulation of the potential difference was obtained on addition to the buffer of a substrate such as glucose or bile acid (Fig 3), or abolished after addition of the metabolic inhibitor dinitrophenol (Fig 4). Similarly removal of oxygen resulted in a fall of potential difference, which recovered when the oxygen supply was replaced.

Consistency of tissue wet weight and extracellular space

Both wet weight (Table IA) and extracellular space (Table IB) remained constant over the 45 minute incubation period after equilibration between the extracellular space and the bulk buffer had been reached.

\section{TAUROCHOLIC ACID KINETICS}

Taurocholic acid tissue uptake (Fig 5) and transport (Fig 6) followed a biphasic pattern with increasing concentration. An initial rapid rate of transport and uptake was followed by slower but consistent movement. The initial rate is assumed to represent active plus passive transport, the slower rate, which is directly related to initial substrate concentrations (correlation coefficient $r=0.99$ ), represents purely passive absorption. It is clear from Figure 5 that at high concentrations of substrate, a line drawn through the experimental points represents both passive and active transport after equilibrium has been reached. A second line, drawn through the origin and lying parallel to the experimental points represents purely passive absorption. Subtraction from the total transport rate of the passive transport component results in a curve representing only the active system. This follows Michaelis-Menten kinetics and has an estimated $\mathrm{K}_{\mathrm{m}}$ of $10 \mu \mathrm{mol} / \mathrm{l}$, an uptake $J_{\max }$ of $40 \mu \mathrm{g} / \mathrm{g}$ wet weight $/ 45$ minutes, and a transport $J_{\max }$ of $4 \mu \mathrm{g} / \mathrm{g}$ wet weight $/ 45$ minutes. Between five minutes and 45 minutes the graph of taurocholic acid tissue uptake rate is a straight line, indicating a constant rate of transport. Transport across the mucosal membrane did not reach measurable levels until after 20 minutes.

TABLE II The coefficient of variation $(C V)$ of tissue uptake of taurocholic acid in 10 patients using a standard buffer with 10 $\mu$ mol/l taurocholic acid

\begin{tabular}{|c|c|c|c|c|}
\hline \multicolumn{5}{|c|}{ Tissue uptake } \\
\hline \multirow[b]{2}{*}{$\begin{array}{l}\text { Patient } \\
\text { no }\end{array}$} & \multirow[b]{2}{*}{$\begin{array}{l}\text { Chamber } \\
\text { no }\end{array}$} & \multicolumn{2}{|c|}{$(\mu \mathrm{g} / \mathrm{g}$ wet weight $/ 45 \mathrm{~min})$} & \multirow[b]{2}{*}{$C V$} \\
\hline & & Mean & $(S D)$ & \\
\hline 1 & 6 & $18 \cdot 1$ & $3 \cdot 2$ & $17 \cdot 7$ \\
\hline 2 & 6 & $17 \cdot 4$ & 1.7 & $9 \cdot 7$ \\
\hline 3 & 5 & $14 \cdot 1$ & 3.0 & $21 \cdot 2$ \\
\hline 4 & 13 & $13 \cdot 3$ & $3 \cdot 3$ & $24 \cdot 8$ \\
\hline 5 & 6 & $15 \cdot 2$ & 2.9 & 19.0 \\
\hline 6 & 6 & $11 \cdot 7$ & $1 \cdot 2$ & $10 \cdot 2$ \\
\hline 7 & 5 & $11 \cdot 5$ & $3 \cdot 1$ & 26.9 \\
\hline 8 & 7 & 16.0 & $3 \cdot 1$ & $19 \cdot 4$ \\
\hline 9 & 5 & 16.9 & $2 \cdot 4$ & $14 \cdot 2$ \\
\hline 10 & 5 & 10.9 & $0: 9$ & 8. \\
\hline
\end{tabular}




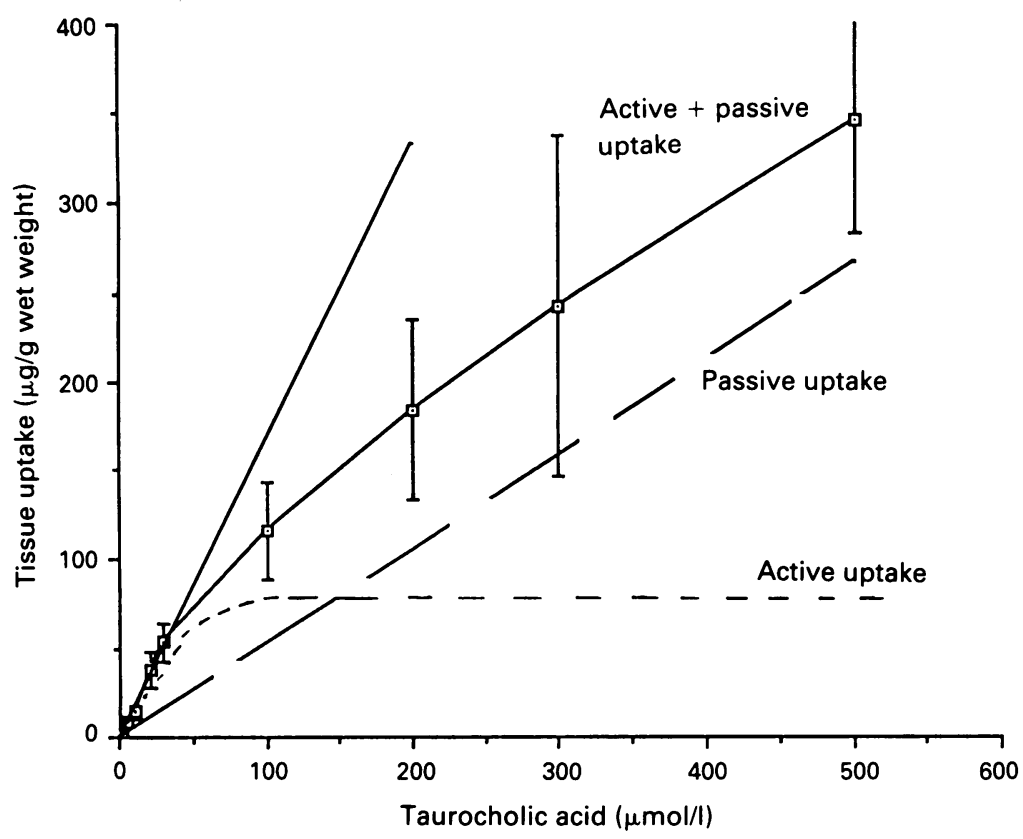

Figure 5: Tissue uptake $\mathrm{v}$ taurocholic acid concentration. (Each point represents the mean $(S D)$ of at least 9 chambers.)

\section{Effect of inhibitors}

There is a significant decrease in both uptake (Fig 7, p <0.001) and transport (Fig 8, p <0.001) in the presence of inhibitors (Student's $t$ test).

\section{Bile acid secretion}

There is very little tissue uptake (Fig $7, \mathrm{p}<0.001$ ) or transport (Fig $8, \mathrm{p}<0.001$, Student's $t$ test) in the secretory direction implying a unidirectional absorptive system.

\section{Effect of sodium depletion}

Using an isosmolar solution of choline chloride to replace sodium chloride in the test buffer results in a significant decrease in tissue uptake (Fig 7, p $<0.001$ ) and transport (Fig 8, p $<0.001$, Student's $t$ test).

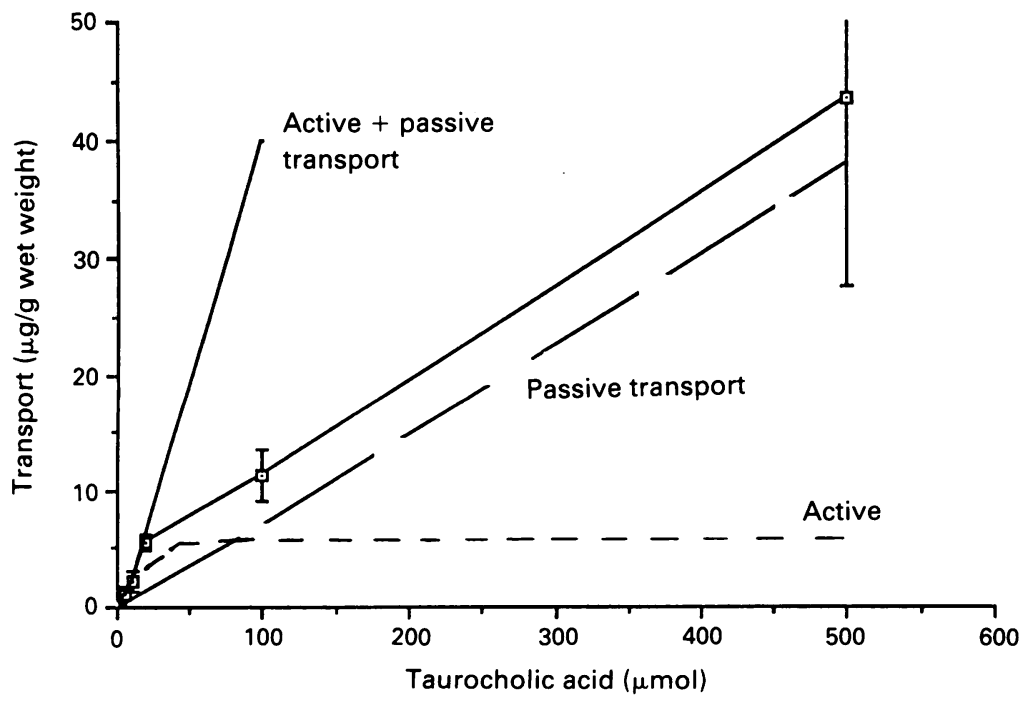

Figure 6: Tissue transport $\mathrm{v}$ taurocholic acid concentration. (Each point represents the mean (SD) of at least 9 chambers.)
TABLE III Tissue uptake and transport of taurocholic acid (TA) in different patient groups

\begin{tabular}{lllc}
\hline & $\begin{array}{l}\text { Ulcerative } \\
\text { colitis }\end{array}$ & Cancer & Constipation \\
\hline Patients (no) & 10 & 6 & 8 \\
Chambers (no) & 60 & 37 & 54 \\
TA uptake $^{\star}$ & $13.48(3.3)$ & $13.4(4 \cdot 8)$ & $12 \cdot 86(3.8)$ \\
TA transport $^{\star}$ & $1 \cdot 3(0 \cdot 83)$ & $0.98(0 \cdot 86)$ & $0.8(0 \cdot 8)$ \\
\hline
\end{tabular}

^Units $=\mu \mathrm{g} / \mathrm{g}$ wet weight/45 minutes.

Reproducibility

The reproducibility in 10 patients is shown in Table 2 . The mean coefficient of variation (C.V.) is $17 \%$, range $8-24 \%$.

\section{Clinical groups}

Preliminary results (Table III) showed no significant difference in tissue uptake or transport of taurocholic acid in patients with constipation, cancer, and ulcerative colitis.

\section{Discussion}

Studies on human ileal mucosal absorption of bile acid are rare. Work by Borgstrom et al ${ }^{1}$ using ingested ${ }^{35} \mathrm{~S}$-taurocholate did not include a specific or quantitative assessment of ileal mucosal function. Similarly work by Krag and Phillips $^{2}$ using intubation and local perfusion of isolated segments is perhaps difficult to interpret becaue of inherent problems with the technique and the fact that only a small number of patients were studied. More recently ileal bile acid absorption has been studied using brush border membrane vesicles. ${ }^{23}$ This method, designed to assess apical membrane bile acid transport, requires complex and exacting biochemical analysis of an in vitro situation which is not strictly comparable with movement through an intact intestinal mucosa.

In this paper, we report a technique which enables quantitative study, under controlled conditions, of both tissue uptake and transport of substrate across an intact epithelial membrane stripped of underlying muscularis. The miniature flux chamber technique produced results for sodium and water absorption which were similar to those of other in vivo and in vitro techniques. ${ }^{24}$ It offers exciting potential for the comparison of intestinal function in different patient groups and their response to treatments. The technique has several advantages over other in vitro techniques, particularly that only small tissue specimens $(0.6 \mathrm{~cm}$ diameter $)$ are required. This allows a large number of experiments to be performed on limited amounts of tissue: especially valuable for kinetic studies.

The chamber is simple to use. The tissue sample is held in position by the clamping action of the two hemichambers. The small volumes of buffer used means that discrete changes in concentration can be detected with a resulting increased sensitivity. Maintenance of tissue orientation allows mucosal to serosal $(M \rightarrow S)$ and serosal to mucosal $(S \rightarrow M)$ transport to be studied simultaneously. Further, the use of site specific inhibitors such as ouabain which inhibits $\mathrm{Na}-\mathrm{K}$ ATPase only at the basolateral membrane, 


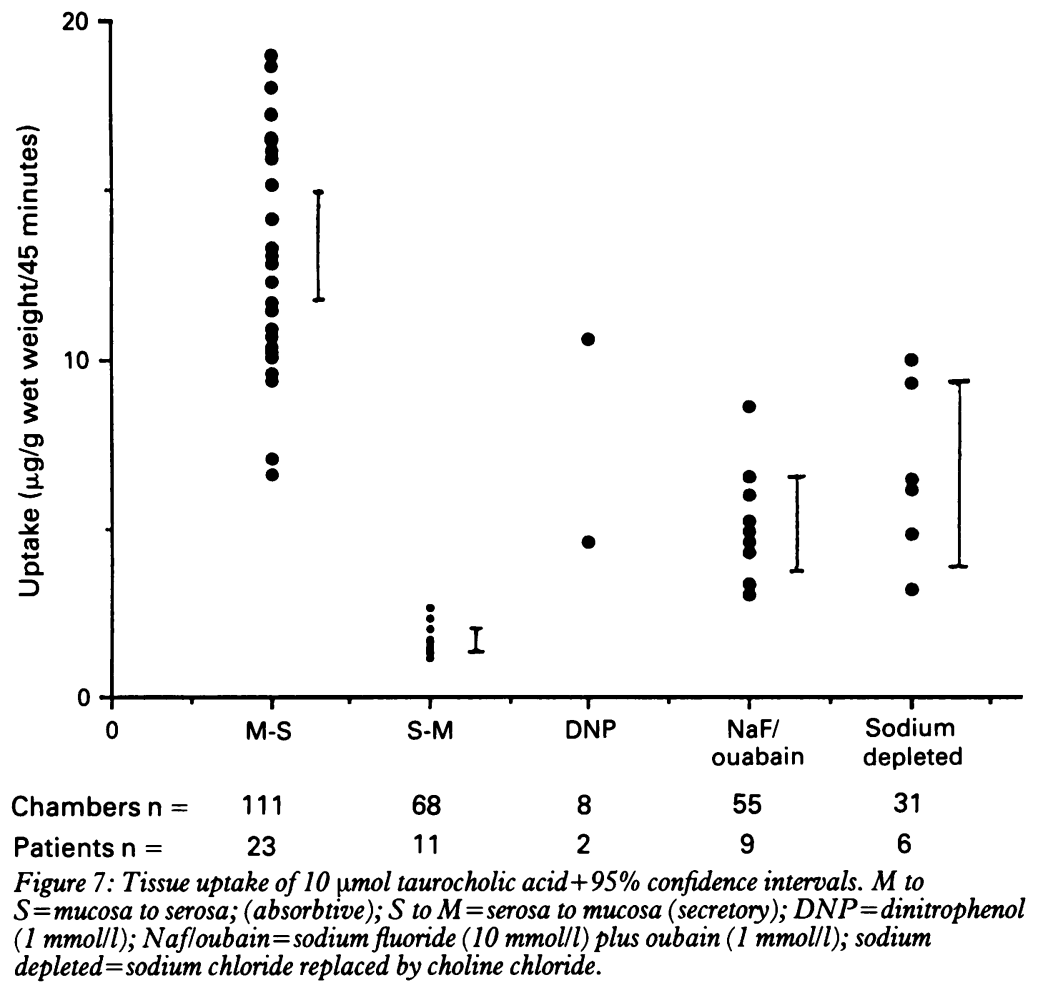

2,4-DNP which is an uncoupler of oxidative phosphorylation, and sodium fluoride which inhibits glycolysis potentially allows transport mechanisms to be studied in detail. Another important aspect of the technique is the removal of the muscle and connective tissue layers from the absorptive mucosa. This process removes a long diffusion pathway which delays absorption process and access of active substrates or inhibitors. ${ }^{2+26}$ These muscle layers would not normally be a barrier in vivo because the circulation of both blood and lymph normally would remove

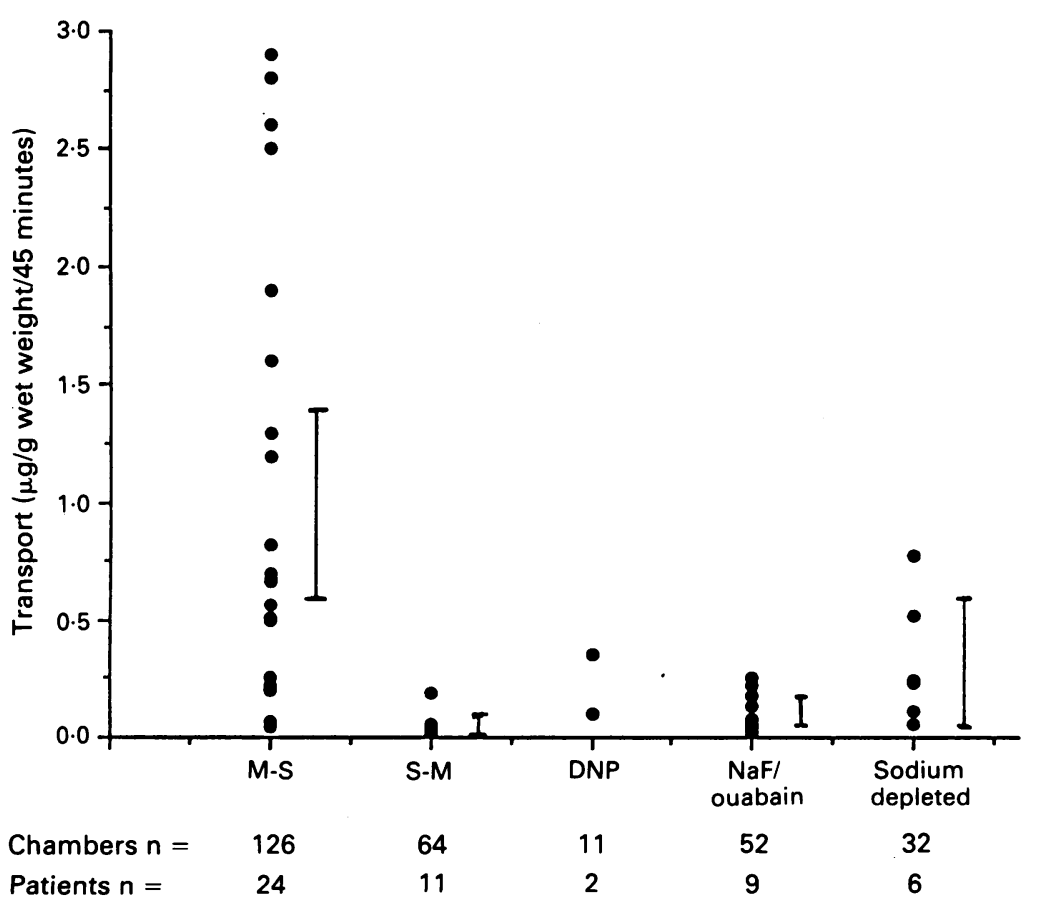

Figure 8: Transport of $10 \mu \mathrm{mol}$ taurocholic acid $+95 \%$ confidence intervals. Abbreviations as in Figure 7. transported materials and metabolites from the epithelia.

Viability studies have shown that dissection and mounting of the tissue in the experimental chamber did not adversely affect the absorptive mucosa. Histological examination confirmed that the dissection had separated the muscle layers from the mucosa.just below the lamina propria and that normal cellular morphology and villous architecture was maintained. Tissue viability and the continued activity of cellular metabolic processes was confirmed in several experiments.

The ability of the tissue to maintain a constant wet weight with increasing time continued normal function and active metabolism. Intracellular electrolyte and fluid balance are regulated and this is confirmed by the lack of cell swelling and a constant extracellular space volume. The low levels of the intracellular enzyme lactate dehydrogenase found in the buffers after incubation confirm that even subtle cellular membrane damage was minimal. ${ }^{27}$

The maintenance of metabolic activity is also demonstrated by a sustained transmucosal potential difference across the membrane. In living epithelia an electrical potential difference exists between the mucosal and serosal sides of the membrane as a result of the sodium 'pump' which actively transfers ions down their electrochemical gradient. ${ }^{28}$ Maintenance of potential difference is evidence of a viable tissue preparation since energy is required to maintain the gradient. The potential difference also is sensitive to the tissue environment. The tissue was stimulated on addition of glucose, or inhibited by anoxia, dinitrophenol, and a combination of sodium fluoride and ouabain, resulting in an increased or decreased potential difference. The stimulation of potential difference with glucose which we have demonstrated is similar to that observed by other workers. ${ }^{29} 30$

Together these five tests confirm tissue viability in the preparation. Each test is concerned with a particular aspect of cellular function and the results taken together confirm that the preparation in vitro is structurally intact with normal metabolic function.

Previous studies have shown that substrate in the bulk buffer may take up to 5 minutes to equilibrate with the extracellular space..$^{22}$ In experiments with short time periods the initial uptake of substrate therefore tends to be overestimated. Ideally, the longer the period of incubation the smaller the error due to time taken to reach equilibrium between the bulk phase and extracellular space. Our results show that between 5 and 45 minutes the rate of taurocholic acid uptake is constant. On the other hand taurocholic acid transport across the mucosal membrane did not reach measurable levels until after 20 minutes. Forty five minutes was chosen as the optimal time for the transport studies since the tissue was still viable, the error due to equilibration with the extracellular space was minimal and significant amounts of taurocholic acid were transported across the membrane.

Amino acids, ${ }^{31}$ sugars, ${ }^{32}$ and bile acids ${ }^{89}$ all undergo active and passive intestinal absorption. 
It is now recognised that active bile acid absorption by ileal enterocytes involves at least two carrier systems. In one of these sodium transport is coupled to a bile acid transporter located in the apical membrane, the other is associated with an anion exchange system located in the basolateral membrane. ${ }^{33}$ Active processes are sensitive to inhibitors and are capable of saturation. Passive absorption is insensitive to inhibitors and apparently linear with respect to substrate concentration. $^{21}$

The results indicate that under conditions of zero concentration gradient of taurocholic acid the membrane is capable of concentrating the bile acid in the absorptive direction. Such a concentrating mechanism may be prevented by metabolic inhibitors, anoxia, or sodium depletion. The lack of transport and uptake in the secretory direction, the reduction of taurocholic acid transport $(M \rightarrow S)$ by inhibitors and by sodium depletion all demonstrate the presence of an active transport system. As the different inhibitors act at different sites it suggests that more than one active transport system for bile acid reabsorption is present.

The isolated mucosa technique was reproducible in control tissue using a standard buffer with $10 \mu \mathrm{mol} / 1$ of taurocholic acid. The high coefficient of variation in tissue from some patients was felt to be due to rough handling of the tissue during what is often a difficult surgical procedure. Variable ischaemia may have resulted from early vascular division when mobilising the ileum prior to resection.

Preliminary results comparing the ability of ileal mucosa to absorb bile acids between patient groups show no significant difference in the patients with constipation, cancer, and ulcerative colitis. These results disagree with those of Van Tilburg, et al,,$^{23}$ who showed reduced bile acid absorption in brush border membrane vesicles of ileum from patients with constipation. However, it is difficult to compare directly the results derived from two such different experimental techniques. Experiments using brush border membrane are designed to assess apical membrane function and are not strictly comparable with measurement of movement through an intact cell. The ability of the isolated mucosa technique quantitatively to assess mucosal bile acid absorption using small biopsy specimens of intact mucosa offers exciting potential for investigation of the pathophysiology of intestinal disease.

It has been demonstrated that the isolated mucosa technique may be used to study human tissue taken at surgery. Preliminary experiments have shown that the transport of bile acid in human ileum has both active and passive mechanisms. The low $\mathrm{K}_{\mathrm{m}}$ obtained for the active mechanism is consistent with a highly efficient absorption process.

This work was supported by a grant from the West Midlands Regional Health Authority and funds from the Research Initiative III of the National Advisory Body for Further and Higher Education. Mr B Panagamuwa was supported by a British Commonwealth Scholarship.
1 Borgstrom HB, Lundh G, Hofmann A. The site of absorption of conjugated bile salts in man. Gastroenterology 1963; 45: 229-38

2 Krag E, Phillips SF. Active and passive bile acid absorption in man: perfusion studies of the ileum and jejunum. $\mathcal{F}$ Clin Invest 1974; 53: 1686-94.

3 Lauterbach F. Passive permeabilities of luminal and basolateral membranes in the isolated mucosal epithelium of guinea pig membranes in the isolated mucosal epithelium of g

4 Partridge S, Davie RJ, Birch NJ. The intestinal absorption of lithium and magnesium in the guinea pig. Magnes Bull 1987; 9: 151-5.

5 Davie RJ, Coleman IPL, Partridge S. Lithium transport in isolated preparations. In: Birch NJ, ed. Lithium: inorganic pharmacology and psychiatric use. Oxford: IRL Press, 1988 $107-11$

6 Davie RJ, Phillips JD, Birch NJ. Trace 89: The absorption of a zinc-histidine complex in isolated guinea pig mucosa. Proceedings Third International Congress on Trace Metals in Health and Disease. Adana, Turkey: Cukerova University Publishing Co, 1991, 325-30.

7 Lack L, Weiner IM. In vitro absorption of bile salts by small intestine of rats and guinea pigs. Am $\mathcal{F}$ Physiol 1961; 200: 313-7.

8 Dowling RH. The enterohepatic circulation. Gastroenterology 1972; 62: 122-33.

9 Glasser JE, Weiner IM, Lack L. Comparative physiology of intestinal taurocholate transport. Am $\mathcal{F}$ Physiol 1965; 208: 359-62.

10 Dietschy JM, Salomon HS, Siperstein MD. Bile acid metabolism. (1) Studies on the mechanisms of intestinal transport. $\mathcal{F}$ Clin Invest 1966; 45: 832-46.

11 Wilson FA, Dietschy JM. Characterisation of bile acid absorption across the unstirred water layer and brush border of the rat jejunum. $\mathcal{F}$ Clin Invest 1972; $51: 3015-25$.

12 Schiff ER, Small NC, Dietschy JM. Characterisation of the kinetics of the passive and active transport mechanism for bile acid absorption in the small intestine and colon of the rat. F Clin Invest 1972; 51: 1351-61.

13 Playoust MR, Isselbacher KJ. Studies on the transport and metabolism of conjugated bile salts by intestinal mucosa f Clin Invest 1964; 43: 467-76.

14 Hislop IG, Hoffman AF, Schoenfield LJ. Determinants of the rate and site of bile acid absorption in man. $\mathcal{F}$ Clin Invest 1967; 46: 1070-1.

15 Switz DM, Hislop IG, Hoffman AF. Factors influencing the absorption of bile acids by the human jejunum. Gastroenterology 1970; 58: 999.

$16 \mathrm{Krebs} \mathrm{H}$, Henseleit K. Unterschungen uber die Harnstoffbilding in Tierkorper. Hoppe-Seylers Z. Physiol Chem 1932; 210: 33-66.

17 Chadwick VS, Phillips SF, Hofmann AF. Measurements of intestinal permeability using low molecular weight polyethy lene glychols (PEG-400). Gastroentrology 1977; 73: 241-6.

$18 \mathrm{Ma}$ TY, Hollander D, Krugliak P, Kantz K. Peg 400, A hydrophilic molecular probe for measuring intestinal permeability. Gastroenterology 1990; 98: 39-46.

19 Evans DF, Pye G, Bramley R, Clark AG, Dyson TJ, Hardcastle JD. Measurement of gastrointestinal $\mathrm{pH}$ profiles in normal ambulant human subjects. Gut 1988; 29: 1035-41.

20 Chattopadhyay G, Kumar D, Keighley MRB, Oya M. Ileal pouch $\mathrm{pH}$ : a regulatory mechanism for evacuation. Gut 1990; 30: Al171.

21 Debnam ES, Levine RJ. An experimental method of identifying and quantifying the active transfer electrogenic coming and quantifying the active transfer electrogenic component from the diffusive component during sugar

22 Cox TM, Peters TJ. The kinetics of iron uptake in vitro by human duodenal mucosa: studies in normal subjects. F Physiol 1979; 289: 469-78.

23 Van Tilburg AJP, De Rooij FWM, Van Blankenstein M, Van den Berg JWO, Bosman-Jacobs EP. Na dependent bile acid transport in the ileum: the balance between diarrhoea and constipation. Gastroenterology 1990; 98: 25-32.

24 Lauterbach F. Ion fluxes in isolated guinea pig intestinal mucosa. In: Robinson JWL, ed. Intestinal ion transport. Lancaster, MTP Press, 1976: 51-74.

25 Barr HB, Riegelman S. Intestinal drug absorption and metabolism. I Comparison of methods and models to study metabolism. I Comparison of methods and models to study physiological factors of in vivo and in

26 Binder HJ, Rawlins CL. Electrolyte transport across isolated large intestinal mucosa. Am f Physiol 1973; 225: 1232-9.

27 Towler CM, Pugh-Humphries GP, Porteous JW. Characterization of columnar absorptive epithelial cells isolated from rat jejunum. $\mathcal{F}$ Cell Sci 1978; 29: 53-75.

28 Clarkson TW, Cross AC, Toole SR. Electrical potentials across isolated small intestine of the rat. Am F Physiol 1961; 200: 1233-5.

29 Barry RJC, Dikstein S, Matthews J, Smyth DH, Wright EM. Electrical potentials associated with intestinal sugar transfer. F Physiol 1964; 171 : 316-38.

30 Salas-Coll CA, Blendis LM, Edmonds CJ. Effect of sugars and cations of the small intestine transepithelial pd in man. Gut 19.75; 16: A844.

31 Murillo F, Delgardo MJ, Murillo ML, Bolufer J. Amino acid absorption in jejunum of rats in vivo - a kinetic comparison of distal resection effects. Comp Biochem Physiol 1986; 84: 455-7.

32 Dawson DJ, Burrows PC, Lobley RW, Holmes R. The kinetics of monosaccharide absorption by human jejunal biopsies: Evidence for active and passive processes. Digestion 1987; 38: 124-32

33 Wilson FA. Intestinal transport of bile acids. Am f Physiol 1981; 4: G83-92. 